\title{
Identification of care needs of patients with and without the use of a classification instrument
}

\author{
IDENTIFICAÇÃO DE NECESSIDADES DE CUIDADOS DOS PACIENTES COM E SEM \\ USO DE INSTRUMENTO DE CLASSIFICAÇÃO
}

\author{
IDENTIFICACIÓN DE LAS NECESIDADES DE CUIDADOS A LOS PACIENTES CON Y SIN \\ EL EMPLEO DE INSTRUMENTO DE CLASIFICACIÓN
}

Marcia Galan Perroca ${ }^{1}$, Marli de Carvalho Jericó', Josi Vaz de Lima Paschoal²

\begin{abstract}
Objective: To analyze the agreement and disagreement between the assessments by applying or not a patient classification instrument, and to investigate the association between the agreement and personal and professional characteristics of the evaluators. Method: This is a descriptive exploratory study. 105 patients were hospitalized in a teaching hospital in the state of Sao Paulo, using the kappa statistic (weighted) and the Bootstrap method. Results: The agreement between the assessments were: $k_{w} 0.87$ (instrument $x$ internal evaluator), $\mathrm{k}_{\mathrm{w}} 0.78$ (instrument $\mathrm{x}$ external evaluator) and $k_{w} 0.76$ (between evaluators) and the influence of some personal and professional characteristics. The assessments conducted through the use of an instrument contemplated a greater number of areas of care in relation to when the instrument was not applied. Conclusion: The use of this instrument is recommended in order to more effectively identify care needs of patients.
\end{abstract}

\section{DESCRIPTORS}

Nursing assessment

Patients

Classification

Needs assessment

\section{RESUMO}

Objetivo: Analisar a concordância e a discordância entre as avaliações realizadas mediante a aplicação ou não de instrumento de classificação de pacientes, e investigar a associação entre a concordância e as características pessoais e profissionais dos avaliadores. Método: Trata-se de um estudo descritivo exploratório. Foram investigados 105 pacientes internados em hospital de ensino do interior do Estado de São Paulo utilizando-se a estatística kappa (ponderado) e o método Bootstrap. Resultados: A concordância entre as avaliações apontou: kw 0,87 (instrumento $x$ avaliador interno), kw 0,78 (instrumento $x$ avaliador externo) e kw 0,76 (entre os avaliadores) e a influência de algumas características pessoais e profissionais. As avaliações conduzidas mediante o uso de instrumento contemplaram maior número de áreas de cuidado em relação a quando o instrumento não foi aplicado. Conclusão: Recomenda-se o uso deste instrumento a fim de se obter identificação mais efetiva das necessidades cuidativas dos pacientes.

\section{DESCRITORES}

Avaliação em enfermagem

Pacientes

Classificação

Determinação de necessidades de

cuidados de saúde

\section{RESUMEN}

Objetivo: Analizar la concordancia y la discordancia entre las evaluaciones realizadas mediante la aplicación o no de un instrumento de clasificación de pacientes e investigar la asociación entre la concordancia y las características personales y profesionales de los evaluadores. Método: Estudio descriptivo exploratorio. Se investigaron a 105 pacientes internados en hospital universitario del interior del Estado de São Paulo utilizándose la estadística kappa (ponderado) y el método Bootstrap. Resultados: La concordancia entre las evaluaciones reveló: kw 0,87 (instrumento $x$ evaluador interno), kw 0,78 (instrumento $x$ evaluador externo) y kw 0,76 (entre los evaluadores) y la influencia de algunas características personales y profesionales. Las evaluaciones conducidas mediante el empleo de instrumento contemplaron mayor número de áreas de cuidado en comparación a cuando no se aplicó el instrumento. Conclusión: Se recomienda el uso de este instrumento a fin de lograr una identificación más efectiva de las necesidades de cuidados a los pacientes.

\section{DESCRIPTORES}

Evaluación en enfermería

Pacientes

Clasificación

Evaluación de necesidades

${ }^{1} \mathrm{PhD}$ Professor. Department of Specialized Nursing, Faculty of Medicine of Sao Jose do Rio Preto, Sao Jose do Rio Preto, SP, Brazil. ${ }^{2}$ MSc in Health Sciences, Faculty of Medicine of Sao Jose do Rio Preto, Sao Jose do Rio Preto, SP, Brazil. 


\section{INTRODUCTION}

The nursing assessment aims to identify care needs of the patient/family in their various dimensions, providing the scientific basis for targeting behaviors and implementing care interventions ${ }^{(1)}$. The importance of the critical appraisal as a component of assessment in the decisionmaking process in nursing practice has been highlighted in the literature. Critical appraisal covers a process in which different types of clinical information about the patient are used to conduct an assessment of the current situation of their state of health ${ }^{(2)}$.

The accuracy of this critical appraisal affects the quality of the decision. Thus, inaccurate or improperly combined critical appraisals produce poor decisions ${ }^{(3)}$. The use of information that has no use for the judgment in question and assigning excessive importance to certain information have been identified ${ }^{(4)}$ as causes of inaccuracy. On the other hand, the misinterpretation of data can lead to loss of time and energy, dissatisfaction and harm to patients and also reduce the favorable outcomes of the care provided $^{(5)}$. It is important to note that professional critical appraisal is founded on clinical experience, which is the precursor of expertise ${ }^{(2)}$

Clinical reasoning has been found in the literature as synonymous with clinical critical appraisal and decision making ${ }^{(2,6)}$ and defined as the representation of intellectual processes involved in patient care, incorporating knowledge standards (empirical, ethical, personal and aesthetic) and critical appraisal(7). Fluency, flexibility and elaboration are considered capabilities involved in the process. Fluency is the multiple thoughts of human beings; flexibility, the ability to switch from one thought to another allocated in another category; and the elaboration is the identification of the implications from an information ${ }^{(8)}$.

In recent decades, measurement scales have been increasingly used by nurses in the assessment process to provide greater assertiveness to decision making in managing care $^{(9)}$. Among them, the Patient Classification Instrument $(\mathrm{PCl})$, built with the purpose of identifying the demand for patient care in relation to nursing, so that categories could be grouped later (minimum, intermediary, semi intensive, intensive) $)^{(9)}$. Its application enables the provision of data relating to patients, so that decision making may be made based on care planning, staff adjustments, productivity and costs of nursing services ${ }^{(10-11)}$.

A Patient Classification Instrument $(\mathrm{PCl})$, developed in Brazil in the late 1990s, has been subjected, over the years, to several tests to evaluate its psychometric properties $^{(9,12-13)}$. Although the results have shown evidence of reliability and validity of the scale and that it can be used to guide management practice in determining the workload of the nursing staff ${ }^{(13)}$, it becomes important to further investigate this instrument, even though the demand for nursing care for the patient is identified by the perception of nurses.
Although one can find in the literature approaches to the development and validation of instruments for classification, it has not been possible to identify investigations comparing the care demand of patients identified by applying $\mathrm{PCl}$ with the nurses perceptions of patient's care demand. We highlight research conducted in Finland ${ }^{(14)}$, where areas of care contained the classification instrument which were contrasted with the patient's perception of their own care needs. It is still unknown whether factors such as being allocated in patient unit or having experience in caring for patients of critical units, such as an ICU, interfere with the agreement of the nurse when they use different forms of assessments for patient's needs. With a patient in a critical condition, for instance, nurses require more frequent assessments than patients in other categories of care, allowing greater opportunity for the development of expertise.

Thus, this study aims to: analyze the agreement and disagreement between the assessments by applying or not a patient classification instrument and to investigate the association between the agreement and the personal and professional characteristics of the evaluators.

\section{METHOD}

This is a quantitative research approach, with crosssectional design, for the assessment of a diagnostic method using a validated $\mathrm{PCl}$ as a gold standard, which was conducted in a private teaching hospital for extra capacity, located in the State of Sao Paulo. We propose to answer the following questions: what is the level of agreement between assessment of categories of care/ needs of patients obtained by applying or not the instrument of classification? In which aspects do these evaluations come closer or move away? Do professional features such as function, time of practice, academic and professional qualification influence in the agreement between the evaluations?

Data were collected during the months of May/2010 to January/2011, along with 105 adult patients at six inpatient units designed to Unified Health System patients. These would incorporate a medical clinic, a medical-surgical clinic and four specialized units (Infectious-parasitic diseases, Unit of Obstetrics and Gynecology, Neurology Unit and Intensive Care Unit for adult - ICU).

At first, the study subjects totaled 13 nurses (clinical care and supervisors), from which six applied the $\mathrm{PCl}^{(9)}$ and seven conducted evaluations without the use of the instrument. It is worth noting that the nursing supervisors, from the units investigated, also developed clinical care activities. In the subsequent stage, in which we found the correlation of personal and professional characteristics with agreement in evaluations, there were seven nurse subjects. 
In order to make the sample representative regarding the professional profile of participants, we established two criteria: be active nurse investigated in units; present different combinations of professionals features (function, time of practice in the unit, professional and academic qualification) and personal characteristics (age). Of the 22 nurses located in the investigated units, only 13 met the inclusion criteria.

Seven variables were investigated. They were: age (less/greater than 30 years); function (clinical nurse or supervisor); time of professional experience (less/more than five years); time working in the unit (less/more than two years); professional qualification completed (certified courses in the area in which they work or related); academic qualification completed (stricto sensu graduate programs - master's and doctoral level), and work in an ICU or other hospitalization unit.

Three instruments for data collection were used. The first consisted of a questionnaire to characterize the participating nurses, containing semi-structured questions about personal and professional data.

The second instrument was the use of a new validated version of a patient classification instrument ${ }^{(9,13)}$, applied to identify the demand for care of patients in relation to nursing. This scale is composed of nine areas of care and classifies patients as: minimum care (9-12 points), intermediary care (13-18 points), semi intensive care (19-24 points) and intensive care (25-36 points). The nine areas of care considered in the composition of the instrument are: Care Process Planning and Coordination, Investigation and Monitoring, Personal Hygiene and Eliminations, Skin Integrity, Nutrition and Hydration, Locomotion or Activity, Therapeutics, Emotional Support, and, Health Education.

The third instrument used consisted of a form for registration of evaluations by clinical reasoning of nurses, and it was designed in two parts. The first addressed the identification data of the patient and evaluator, as well as date and time of data collection. The second was intended for the actual assessment, where evaluators were asked to list and justify the care needs of patients. Subsequently, these evaluators would choose from a list of four categories, similar to the $\mathrm{PCl}$ (minimum care, intermediary care, semi intensive care and intensive care) and their definitions, the category that expressed more accurately the demand for patient care in relation to Nursing. Each patient was evaluated three times:

1. Upon application of the $\mathrm{PCl}$ by a nurse from the hospitalization unit;

2. No application of the PCI by a nurse from the patient's hospitalization unit (internal evaluator - IE);

3. No application of the $\mathrm{PCl}$ by a nurse from another patient's hospitalization unit (external evaluator - EE).
Nurses were asked to independently evaluate the assigned patients without exchanging information with each other during the process. Observation about the shortest possible time between assessments was also recommended in order to prevent changes in clinical status of patients, which would interfere in the results.

All nurses were placed during daytime. The preference for this period was due to the greater possibility of the nurse/bed and greater knowledge of patient care needs. Respecting the ethical issues involved in research, we obtained a Consent Form from the professionals involved and it was approved by the Research Ethics Committee (N. 399/2009).

The weighted Kappa $\left(\mathrm{K}_{\mathrm{w}}\right)$ with $95 \%$ confidence interval (CI) was chosen to verify the level of agreement between assessments in respect of different categories of care. Disagreements were categorized into three levels, considering grade 1, when the patient was classified as a category of care immediately above or below (minimum/intermediate care or intermediate/minimum care), and so on for the other grades. Interpretation of data for the level of agreement followed the subsequent default values ${ }^{(15)}$ : $<0.20$ = poor; $0.21-0.40=$ fair $; 0.41-0.60=$ moderate; $0.61-$ $0.80=$ good and $0.81-1.00=$ very good.

The cross mapping ${ }^{(16)}$, adapted to the purposes of this study, was used to analyze the justifications of nurses as demand for care of patients and categorize them according to the nine areas of $\mathrm{PCl}$. For each characteristic to be compared, one resampling was performed of 1000 bootstrap samples of the coefficient classified according to category of care and reclassified as minimum/intermediary and semi intensive/intensive. This is a resampling method for intensive computing, designed to generate distributions of functions of the difficult data to be obtained by probabilistic calculations, according to the levels of the variables chosen, as in this case $\mathrm{e}^{(17)}$.

Statistical analysis was performed by applying the software Rx64 2.13.0 version of The R Foundation for Statistical Computing, 2011. Descriptive statistical data are presented as frequency, percentage, mean and standard deviation.

\section{RESULTS}

There was a prevalence of female patients $(n=65 ; 61.9 \%)$, mean age of $52.5(S D=18.7)$ range $15-93$ years. Through the classification instrument, patients were categorized into minimum care $(n=51 ; 48.6 \%)$, intermediary care $(n=27 ; 25.7 \%)$, semi intensive care $(n=15 ; 14.3 \%)$ and intensive care $(n=12 ; 1.4 \%)$.

Evaluators composed a sample of mostly female (12/13 nurses) with a mean age of 35.6 (SD=9.4) - range 24-52 years. The average time of professional practice was $8.3(S D=5.7)$ years, and working in the unit of $4.9(S D=4.8)$ years. Two nurses were placed in the ICU and eleven 
worked in other hospitalization units involved in the study; eight of them worked as a clinical care nurse and five were supervisors. With regard to professional qualifications, a nurse stated having only graduation degree, three attended nursing continuing education courses, eight had a certification degree, six of them in areas where they worked or related to it, and one nurse had a master's degree.

\section{Agreement and disagreement between assessments}

A total of 315 assessments were performed, being 105 and 210 , respectively, with and without application of the patient classification instrument. The categories of care by type of evaluator and the agreement between different types of assessment (with and without $\mathrm{PCl}$ ) and evaluators (internal and external) are presented, respectively, in Tables 1 and 2 . Regarding the care category, there was greater agreement between the assessments in the categories of minimum and intensive care (Table 1 ). The $\mathrm{K}_{w}$ (instrument $x$ evaluator type) ranged from $0.76(\mathrm{Cl} 0.62-0.89)$ to 0.87 (Cl $0.74-1.00$ ) and $\mathrm{K}_{w}$ (work or do not work in ICU) of -0.18 (Cl NaN-NaN) to 0.58 (Cl 0.32 - 0.84). NaN (acronym for Not a Number) is not a valid numeric value (Table 2 ).

When there was disagreement, the evaluators classified the patients below or above from the category of care indicated by $\mathrm{PCl}$. The IE classified 16/26 assessments above of the class indicated by the $\mathrm{PCl}$, the same happened to the EE - 31/39 assessments (Figure 1).

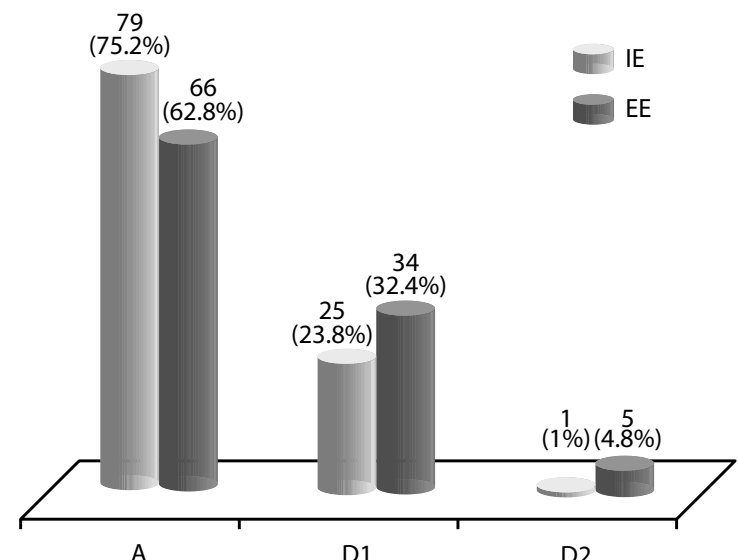

$\mathrm{A}=$ agreement; $\mathrm{D} 1$ = disagreement in $1^{\text {st }}$ degree; $\mathrm{D} 2$ = disagreement in $2^{\text {nd }}$ degree. Agree = agreement. Note: $(\mathrm{N}=105)$. Jose do Rio Preto, 2011 $\mathrm{NICU}=$ no UTI. Note: $(\mathrm{N}=105)$.
Table 1 - Agreement percentage of assessments according to categories of care - Sao Jose do Rio Preto, 2011

\begin{tabular}{lcccccc}
\hline \multirow{2}{*}{ Categories of care } & \multicolumn{2}{c}{ IE $(\mathbf{N}=\mathbf{7 9})$} & \multicolumn{2}{c}{ EE $(\mathbf{N}=\mathbf{6 6})$} & \multicolumn{3}{c}{ IE x EE $(\mathbf{N = 6 7 )}$} \\
\cline { 2 - 7 } & Class & Agree & Class & Agree & Class & Agree \\
Minimum care & 51 & $46(90.2)$ & 41 & $37(90.2)$ & 41 & $37(90.2)$ \\
Intermediary care & 21 & $13(61.9)$ & 24 & $11(45.8)$ & 24 & $9(37.5)$ \\
Semi intensive care & 22 & $11(50)$ & 25 & $9(36)$ & 25 & $12(48)$ \\
Intensive care & 11 & $9(81.8)$ & 15 & $9(60)$ & 15 & $9(60)$ \\
\hline
\end{tabular}

$\mathrm{IE}=$ internal evaluator; $\mathrm{EE}=$ external evaluator; Class = classification;

Table 2 - Kappa agreement level between the assessments - Sao

\begin{tabular}{lcc}
\hline Assessment & $\mathbf{K}_{\mathbf{w}}$ & IC 95\% \\
\hline Instrument x Internal evaluator & 0.87 & $0.74-1.00$ \\
Instrument x External evaluator & 0.78 & $0.64-0.91$ \\
Internal evaluator x External evaluator & 0.76 & $0.62-0.89$ \\
Instrument x ICU internal evaluator & 0.58 & $0.32-0.84$ \\
Instrument x NICU internal evaluator & 0.16 & $\mathrm{NaN}-\mathrm{NaN}$ \\
Instrument x External evaluator ICU & -0.18 & $\mathrm{NaN}-\mathrm{NaN}$ \\
Instrument x External evaluator NICU & 0.39 & $0.13-0.65$ \\
\hline
\end{tabular}

$\mathrm{Kw}=$ weighted Kappa $; \mathrm{IC}=$ confidence interval; $\mathrm{NaN}=$ not a number;

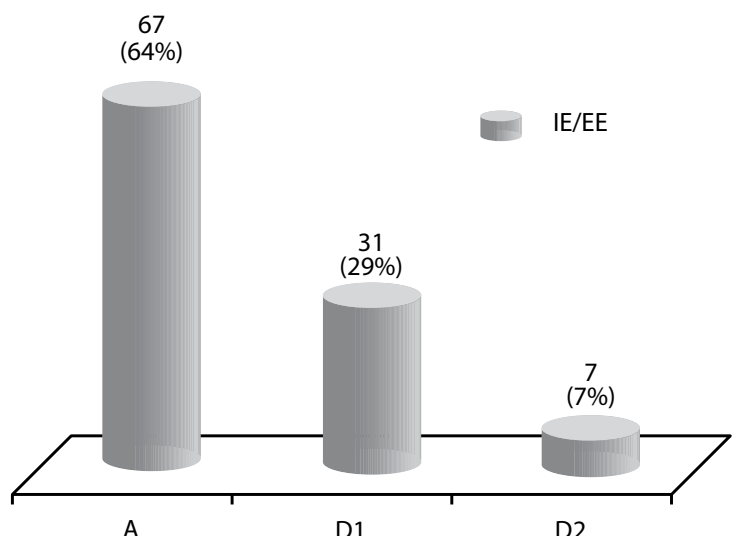

Figure 1 - Comparison between agreement and disagreement in degrees: a) between evaluators and the instrument; $b$ ) among evaluators - Sao Jose do Rio Preto, 2011

The 210 assessments undertaken (IE and EE) generated 738 justifications, of which 73 were discarded due to their lack of relationship with the nine areas of $\mathrm{PCl}$ care. We identified 604 justifications referring to the psychobiological dimension and 53 to psychosocial dimension (Health Education and Emotional Support). On average, $3.2(\mathrm{SD}=1.7)$ (range 1-8) care areas were found, being $2.8(S D=1.8)$ for the IE and $3.5(\mathrm{SD}=1.6)$ for the EE. The most cited areas were Investigations and Monitoring (154 references), Locomotion and Activity (131) and Personal Hygiene and Eliminations (103).

\section{Agreement between the variables}

There was greater agreement for age $\geq 30$ years -0.73 (0.08) (IE) and $0.06(0.11)(\mathrm{EE})$; time of professional practice $\geq 5$ years $-0.73(0.08)$ (IE) and $0.07(0.12)(E E)$, professional qualification - $0.83(0.08)$ (IE) and function of supervisor $0.11(0.14)(E E)$. There was no evidence of difference in degree of agreement, according to job function (clinical nurse or supervisor) and having academic qualification for the IE and having academic qualification for the EE(Figure 2). 
a)
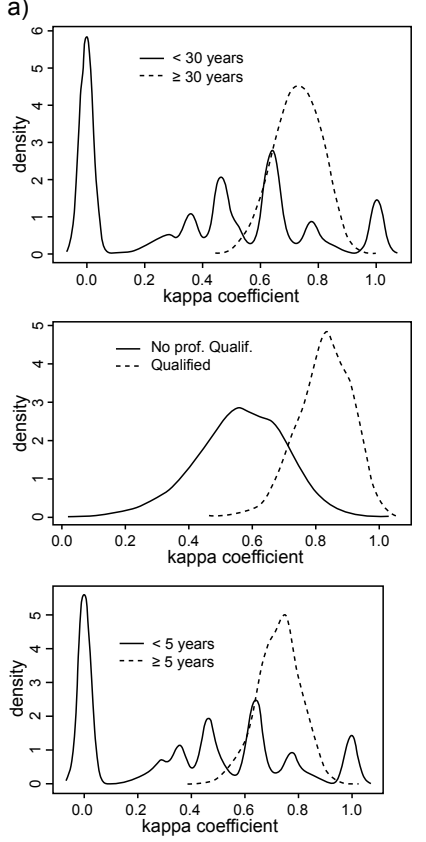
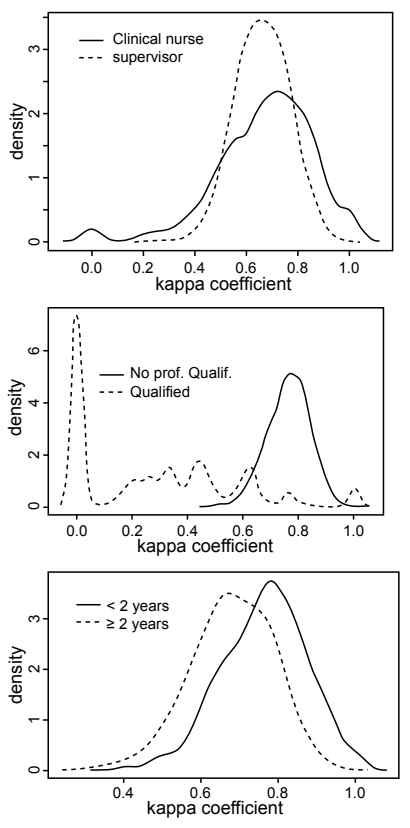

b)
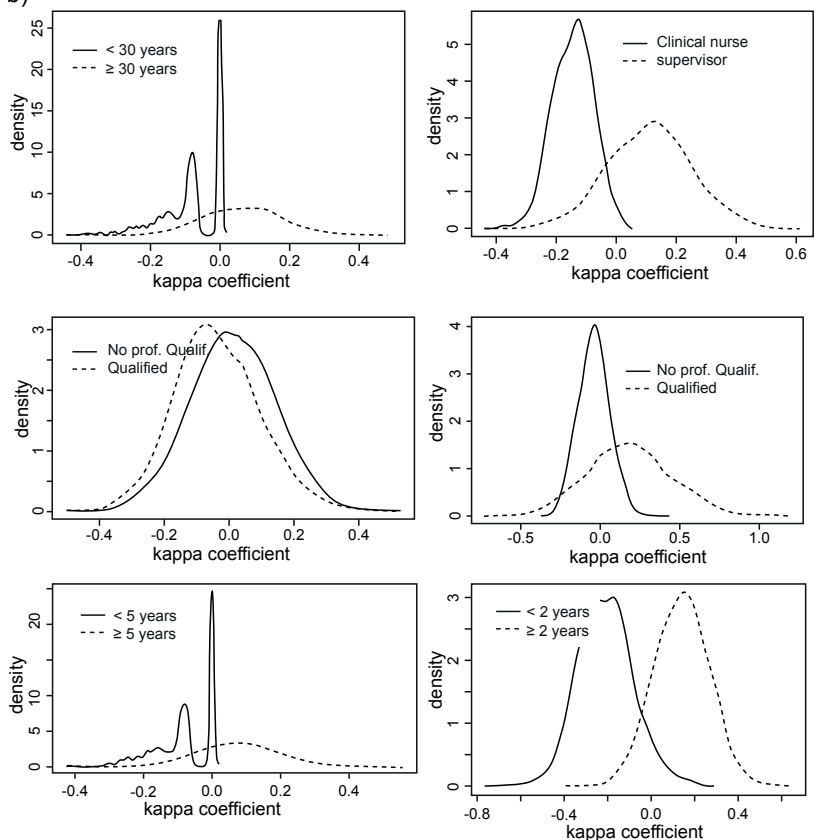

Figure 2 - Degree of agreement among evaluators and the PCI to the variables of age, years of professional experience in the unit, professional and academic qualification and function: a) internal (IE) and b) external (EE) - Sao Jose do Rio Preto, 2011

It was observed that assessments made by nurses placed in the ICU showed greater agreement $0.80(0.11)$ obtained by applying $\mathrm{PCl}$ than those conducted by nurses from other hospital units 0.66 (0.10).

\section{DISCUSSION}

\section{Agreements and disagreements between care categories}

A total of 315 evaluations were made being 105 with application of instrument (for nursing unit) and 210 without the use of the $\mathrm{PCl}$ (for nursing of patient unit - IE and by nurse from another unit - EE).

The findings of this study showed that the internal evaluator (IE) showed very good level of agreement with the instrument $\left(\mathrm{K}_{w} 0.87-\mathrm{Cl} 0.74-1.00\right)$. This can be justified by the knowledge of the clinical status of patients by establishing patient/family bond ${ }^{(2)}$ and the active participation from the planning to the implementation of the care process. The availability of access to information by the internal evaluator enables higher data processing, making the evaluation process more efficient. It also became clear, as a previous study ${ }^{(12)}$, the extreme categories of care (minimum and intensive) were more consistent for patients presenting demand of nursing care and easily identifiable by nurses.

There was prevalence of disagreement in one degree and a tendency to overestimate the category of care ${ }^{(18-19)}$. The view of the nurse on the patient without the use of $\mathrm{PCl}$, concentrated in the areas of Investigation/
Monitoring, Locomotion/Activity, Therapeutics and Personal Hygiene and Eliminations, regardless of the type of care. Personal Hygiene had already been identified as the most significant area of care in determining the complexity of care ${ }^{(12)}$. Study ${ }^{(20)}$ evaluating the care areas mostly addressed in the nursing patient discharge guidelines showed significant increase of $71.3 \%$ in identifying care needs when $\mathrm{PCl}$ is applied.

Although the external evaluator (EE) noted greater number of justifications corresponding to the areas of care of the $\mathrm{PCl}$, they were less assertive about the categories of patient care in relation to the internal evaluator (IE). However, the evaluators did not cover all of the areas identified by the instrument.

\section{Association between the agreement and the profile of evaluators}

The professional and personal features that had influence on the agreement between the evaluations were age $\geq 30$ years, time of professional practice $\geq 5$ years, professional qualification and being placed in the ICU. The variable function, that is, being a supervisor or a clinical nurse, showed no evidence of difference in degree of agreement for the internal and external evaluators. In the institution investigated, nursing supervisors often take care of clinical care activities due to the quantitative insufficiency of this professional in the team. Thus, this closeness with the assistance may have influenced the results.

Being placed in the ICU had a good level of agreement only when the nurse was in their environment (internal evaluator). This confirms that the context in which the 
assessment takes place and the culture of nursing care in the unit can influence clinical reasoning ${ }^{(2)}$, as well as the patient's knowledge.

A model built related to different levels of acquiring skills in nursing practice ${ }^{(21)}$; described five positions ranging from beginner (novice), with limited recognition of evidence and analytical thinking, to the specialist (expert) with comprehensive understanding and intuition. Thus, the model rests on concepts of experience, knowledge and skills. A more recent study ${ }^{(22)}$ comparing types of nurses selected by experts and novices in the process of decision making in the ICU found that specialist nurses are more proactive in collecting relevant evidence and anticipating problems than novice nurses.

However, not always the most experienced and most qualified nurses achieved more effective assessments. A British study ${ }^{(23)}$ comparing results of applying risk scales of pressure ulcer with assessments by clinical reasoning carried out by 236 nurses found no statistical association between the two evaluation approaches and socio-demographic variables. It was also considered that the pressure exerted by time, reduces the ability of nurses to detect patients' needs and perform interventions, even when the professional has clinical experience ${ }^{(24)}$.

One limitation of this study was the number of patients assessed by nurses, which made it difficult to obtain more

\section{REFERENCES}

1. Bittencourt GKGD, Crossetti MGO. Critical thinking skills in the nursing diagnosis process. Rev Esc Enferm USP [Internet]. 2013 [cited 2014 Feb 10];47(2):341-7. Available from: http:// www.scielo.br/pdf/reeusp/v47n2/en_10.pdf

2. Tanner CA. Thinking like a nurse: a research-based model of clinical judgment in nursing. J Nurs Educ. 2006;45(6):204-11.

3. Harvey N. Studying judgment: general issues. Think Reason [Internet]. 2001 [cited 2013 Nov 10];7(1):103-18. Available from: http://www.tandfonline.com/doi/pdf/10.1080/135467 80042000064\#preview

4. Dowding D, Thompson C. Using judgment to improve accuracy in decision-making. Nurs Times. 2004;100(22):42-4.

5. Lunney M. Critical need to address accuracy of nurses' diagnoses. Online J Issues Nurs [internet]. 2008 [cited 2012 Dec 8];13:(1). Available from: http://nursingworld.org/ MainMenuCategories/ANAMarketplace/ANAPeriodicals/ OJIN/TableofContents/vol132008/No1Jan08/ ArticlePreviousTopic/AccuracyofNursesDiagnoses.html

6. Simmons B. Clinical reasoning: concept analysis. J Adv Nurs. 2010;66(5):1151-8 conclusive results. We found difficulties in moving nurses from their original units and to perform three types of evaluations (instrument, internal and external evaluator) simultaneously. The concern with the time spent out of the unit to perform the evaluations may have been an influential factor in the results. Thus, its replication in other settings with larger samples is recommended, using the same variables and the same criteria to enable comparison of findings.

\section{CONCLUSION}

In professional practice, it is important to select assessment strategies that address the real needs of patients to guide decisions of nurses in care planning and care effectiveness.

The degree of agreement found in evaluations shows that the studied $\mathrm{PCl}$ is aligned with the perception of nurses about the demand for nursing care of the patient, facilitating their reliability and use as a guide to decision making in the management of care. It also shows that the evaluations conducted by using instrument contemplated more areas of care in relation to when the instrument was not applied. Therefore, the use of this instrument is recommended in order to more effectively identify the care needs of patients.

7. Cerullo JASB, Cruz DALM. Clinical reasoning and critical thinking. Rev Latino Am Enfermagem. 2010;18(1):124-9.

8. Lunney M. Uso do pensamento crítico para o alcance de resultados positivos de saúde. In: Lunney $M$. Pensamento crítico para o alcance de resultados positivos em saúde: análise e estudos de caso em enfermagem. Porto Alegre: Artmed; 2011. p. 25-55.

9. Perroca MG. Development and content validity of the new version of a patient classification instrument. Rev Latino Am Enfermagem. 2011;19(1):56-66.

10. De Groot HA. Patient classification system evaluation: Part 2, system selection and implementation. J Nurs Adm. 1989;19(7):24-30.

11. Van Slyck A. Patient Classification Systems: not a proxy for nurse 'busyness'. Nurs Admin Q. 2000;24(4):60-5.

12. Perroca MG, Gaidzinski RR. Análise da validação de constructo do instrumento de classificação de pacientes proposto por Perroca. Rev Latino Am Enfermagem. 2004; 12(1):83-91. 
13. Perroca MG. The new version of a patient classification instrument: assessment of psychometric properties. J Adv Nurs. 2013;69(8):1862-8.

14. Fagerström L, Eriksson K, Engberg IB. The patients's perceived caring needs: measuring the unmeasurable. Int J Nurs Pract. 1999;5(4):199-208.

15. Altman DG. Practical statistics for medical research. London: CRC; 2013.

16. Lucena AF, Barros ALBL. Mapeamento cruzado: uma alternativa para à análise de dados em enfermagem. Acta Paul Enferm. 2005;18(1):82-8.

17. Perera R, Heneghan C, Badench D. Ferramentas estatísticas no contexto clínico. Porto Alegre: Artmed; 2010.

18. Farrel GA. How accurately do nurses perceive patients' needs? A comparison of general and psychiatric settings. J Adv Nurs. 1991;16(9):1062-70.

19. Lauri S, Lepistö $M$, Käppeli S. Patients' needs in hospital: nurses' and patients' views. J Adv Nurs. 1997;25(2):339-46.
20. Pagliarini FC, Perroca MG. Uso de instrumento de classificação de pacientes como norteador do planejamento de alta de enfermagem. Acta Paul Enferm. 2008;21(3): 393-7.

21. Benner P, Tanner C, Chesla C. From beginner to expert: gaining a differentiated clinical world in critical care nursing. ANS Adv Nurs Sci. 1992;14(3):13-28.

22. Hoffman KA, Aitken LM, Duffield C. A comparison of novice and expert nurses' cue collection during clinical decision-making: verbal protocol analysis. Int J Nurs Stud. 2009;46(10):1335-44.

23. Gould D, Goldstone L, Gammon J, Kelly D, Gammon J. Examining the validity of pressure ulcer risk assessment scales: a replication study. Int J Nurs Stud. 2004;41(3): 331-9.

24. Yang H, Thompson C, Bland M. The effect of clinical experience, judgment task difficulty and time pressure on nurses' confidence calibration in a high fidelity clinical simulation. BMC Med Inform Decis Mak. 2012;12(1):113-21. 